\title{
Solitary Hepatic Eosinophilic Granuloma Accompanied by Eosinophilia Without Parasitosis: Report of a Case
}

\author{
Takatsugu Yamamoto ${ }^{1}$, Toru Miyazaki ${ }^{1}$, Yukiko Kurashima ${ }^{1}$, Kazunori Ohata ${ }^{1}$, Masato \\ Okawa $^{1}$, Shogo Tanaka ${ }^{1}$, Takahiro Uenishi ${ }^{1}$, Katsuhiko Miyaji ${ }^{2}$, Nobusuke Fukumoto ${ }^{2}$ \\ ${ }^{1}$ Department of Surgery and ${ }^{2}$ Department of Gastroenterology, Ishikiri Seiki Hospital, Osaka, Japan
}

\begin{abstract}
A 43-year-old Japanese woman visited for a hepatic tumor incidentally found. We suspected eosinophilic granuloma of the liver (EGL) due to visceral larva migrans (VLM). However, neither past history nor medical interview indicated a risk of parasitosis. Blood testing revealed eosinophilia, serum examination showed normal results for immunoglobulin E, and enzyme-linked immunosorbent assay yielded negative for Toxocara and Anisakis. Gastric and colonic endoscopy revealed normal features. Several imagings showed central necrosis of the tumor. After informed consent, laparoscopic resection was performed. Histopathological examination showed EGL without parasites. No recurrence had occurred postoperatively. Most reports documented that EGL are caused by VLM. However, parasites are not always demonstrable on serum, histopathological, or immunochemical examinations. When acting as allergens to induce type I responses, microscopic agents other than parasites in the intestinal tract could induce eosinophilic inflammation in the liver. Accumulation of more cases should help clarify other pathogeneses for EGL.
\end{abstract}

Key words: Eosinophilic granuloma of the liver - Parasitosis - Type I allergy - Toxocara Hepatic granuloma

\begin{abstract}
A lthough systemic eosinophilic granulomas can be caused by various diseases, eosinophilic granuloma of the liver (EGL) is predominantly caused by visceral larva migrans (VLM) caused by
\end{abstract}

Toxocara and Capillaria species. Type I allergic reaction to antigens from the worms has been suggested to induce vasculitis, eosinophilic aggregation, and secondary EGL. We encountered a rare 
case of EGL in which we could not demonstrate any correlation between EGL and VLM, despite various pre- and postoperative examinations. We report this case herein and discuss our speculations.

\section{Case Report}

A 43-year-old Japanese woman visited our hospital with a hepatic tumor that had been incidentally identified on ultrasonography during an annual medical examination. She was married with no children, was born and lived in Osaka, was employed as an office worker, and had no pets. She had no habits of drinking alcohol, smoking, or eating raw meat from mammals or birds. She had not eaten any raw fish during the previous 3 months, and had no relevant medical history or history of drug use. Her temperature was normal, and physical examination revealed no obvious symptom such as icterus, dyspnea, ophthalmopathy, gynecologic abnormality, or abdominal complaints.

Other than an increased level of eosinophils in peripheral white blood cells $(10 \%)$, results of blood cell tests, serologic examinations including immunoglobulin (Ig)G, IgM, IgE, and enzyme-linked immunosorbent assay (ELISA) for Toxocara and Anisakis species were within the normal range (Table 1). Endoscopy of the upper digestive tract and colon revealed normal features.

Ultrasonographic examination showed a single, low-echoic mass with irregular margins $2 \mathrm{~cm}$ in diameter in segment 6 of the liver, and Doppler ultrasonography revealed high arterial flow around the tumor, but no blood flow within the tumor (Fig. 1A). Positron emission tomography showed a standardized uptake value of 2.4 in the tumor (Fig. 1B), while plain CT showed a low-density lesion, and dynamic CT of the liver depicted rim enhancement of the tumor in both early and late phases (Fig. 1C-E). Magnetic resonance imaging (MRI) depicted a slight low-intensity lesion on T1-weighted imaging (Fig. 2A), and gadolinium-ethoxybenzyl-diethylenetriamine pentaacetic acid (Gd-EOB-DTPA) MRI depicted rim enhancement of the tumor in the early phase of T1 (Fig. 2B), and defect of GdEOB-DTPA uptake to the tumor in the late phase of T1 (Fig. 2C, 2D). Imaging series showed no tumors in other organs and no changes in tumor size over the course of 2 months.

We could not reach a clear decision between the differential diagnoses of inflammatory pseudotu-
Table 1 Laboratory data on admission

\begin{tabular}{|c|c|}
\hline \multicolumn{2}{|l|}{ Complete blood count } \\
\hline White blood cells & $5030 / \mu \mathrm{L}$ \\
\hline Red blood cells & $383 \times 10^{4} / \mu \mathrm{L}$ \\
\hline Hemoglobin & $12.8 \mathrm{~g} / \mathrm{dL}$ \\
\hline Hematocrit & $37.40 \%$ \\
\hline Platelets & $17.8 \times 104 / \mu \mathrm{L}$ \\
\hline Neutrophils & $49.10 \%$ \\
\hline Lymphocytes & $33.60 \%$ \\
\hline Monocytes & $5.40 \%$ \\
\hline Eosinophils & $10.70 \%$ \\
\hline Basophils & $1.20 \%$ \\
\hline \multicolumn{2}{|l|}{ Blood chemistry } \\
\hline Total protein & $7.2 \mathrm{~g} / \mathrm{dL}$ \\
\hline Albumin & $3.8 \mathrm{~g} / \mathrm{dL}$ \\
\hline Globulin & $3.4 \mathrm{~g} / \mathrm{dL}$ \\
\hline$\alpha 1$ globulin & $2.80 \%$ \\
\hline$\alpha 2$ globulin & $6.30 \%$ \\
\hline$\beta$ globulin & $6.90 \%$ \\
\hline$\gamma$ globulin & $18.20 \%$ \\
\hline Total bilirubin & $0.7 \mathrm{mg} / \mathrm{dL}$ \\
\hline Aspartate aminotransferase & $22 \mathrm{IU} / \mathrm{L}$ \\
\hline Alanine aminotransferase & $16 \mathrm{IU} / \mathrm{L}$ \\
\hline Alkaline phosphatase & $145 \mathrm{IU} / \mathrm{L}$ \\
\hline Lactate dehydrogenase & $165 \mathrm{IU} / \mathrm{L}$ \\
\hline$\gamma$-glutamyl transpeptidase & $13 \mathrm{IU} / \mathrm{L}$ \\
\hline Cholinesterase & $212 \mathrm{IU} / \mathrm{L}$ \\
\hline Amylase & $82 \mathrm{IU} / \mathrm{L}$ \\
\hline Blood urea nitrogen & $10.5 \mathrm{mg} / \mathrm{dL}$ \\
\hline Creatinine & $0.51 \mathrm{mg} / \mathrm{dL}$ \\
\hline Uric acid & $4.9 \mathrm{mg} / \mathrm{dL}$ \\
\hline Total cholesterol & $213 \mathrm{mg} / \mathrm{dL}$ \\
\hline C-reactive protein & $0.05 \mathrm{mg} / \mathrm{dL}$ \\
\hline $\mathrm{Na}$ & $139 \mathrm{mEq} / \mathrm{L}$ \\
\hline K & $4.4 \mathrm{mEq} / \mathrm{L}$ \\
\hline $\mathrm{Cl}$ & $105 \mathrm{mEq} / \mathrm{L}$ \\
\hline Blood sugar & $81 \mathrm{mg} / \mathrm{dL}$ \\
\hline Hemoglobin A1c & $5.10 \%$ \\
\hline Indocyanine green retention rate at $15 \mathrm{~min}$ & $6 \%$ \\
\hline Type III procollagen-N-peptide & $0.5 \mathrm{U} / \mathrm{mL}$ \\
\hline Type IV collagen 7S & $3.0 \mathrm{ng} / \mathrm{mL}$ \\
\hline \multicolumn{2}{|l|}{ Serology } \\
\hline Hepatitis B surface antigen & Negative \\
\hline Hepatitis B core antibody & Negative \\
\hline Hepatitis B surface antibody & Negative \\
\hline Hepatitis $\mathrm{C}$ virus antibody & Negative \\
\hline Antinuclear antibody & Negative \\
\hline Antimitochondrial antibody & Negative \\
\hline $\begin{array}{l}\text { Enzyme-linked immunosorbent assay } \\
\text { for Toxocara and Anisakis species }\end{array}$ & $<0.1 \mathrm{U}_{\mathrm{A}} / \mathrm{mL}$ \\
\hline Immunoglobulin E & $50.8 \mathrm{IU} / \mathrm{mL}$ \\
\hline \multicolumn{2}{|l|}{ Tumor marker } \\
\hline $\begin{array}{l}\text { Protein induced by vitamin } \mathrm{K} \\
\text { absence/antagonist-II }\end{array}$ & $16 \mathrm{IU}$ \\
\hline Cytokeratin 19 fragment & $1.6 \mathrm{ng} / \mathrm{mL}$ \\
\hline$\alpha$-fetoprotein & $4.9 \mathrm{ng} / \mathrm{mL}$ \\
\hline Carcinoembryonic antigen & $1.3 \mathrm{ng} / \mathrm{mL}$ \\
\hline Carbohydrate antigen 19-9 & $4.1 \mathrm{U} / \mathrm{mL}$ \\
\hline \multicolumn{2}{|l|}{ Coagulation test } \\
\hline Prothrombin time $\%$ & $72.80 \%$ \\
\hline Prothrombin time international & \\
\hline normalized ratio & 1.27 \\
\hline
\end{tabular}




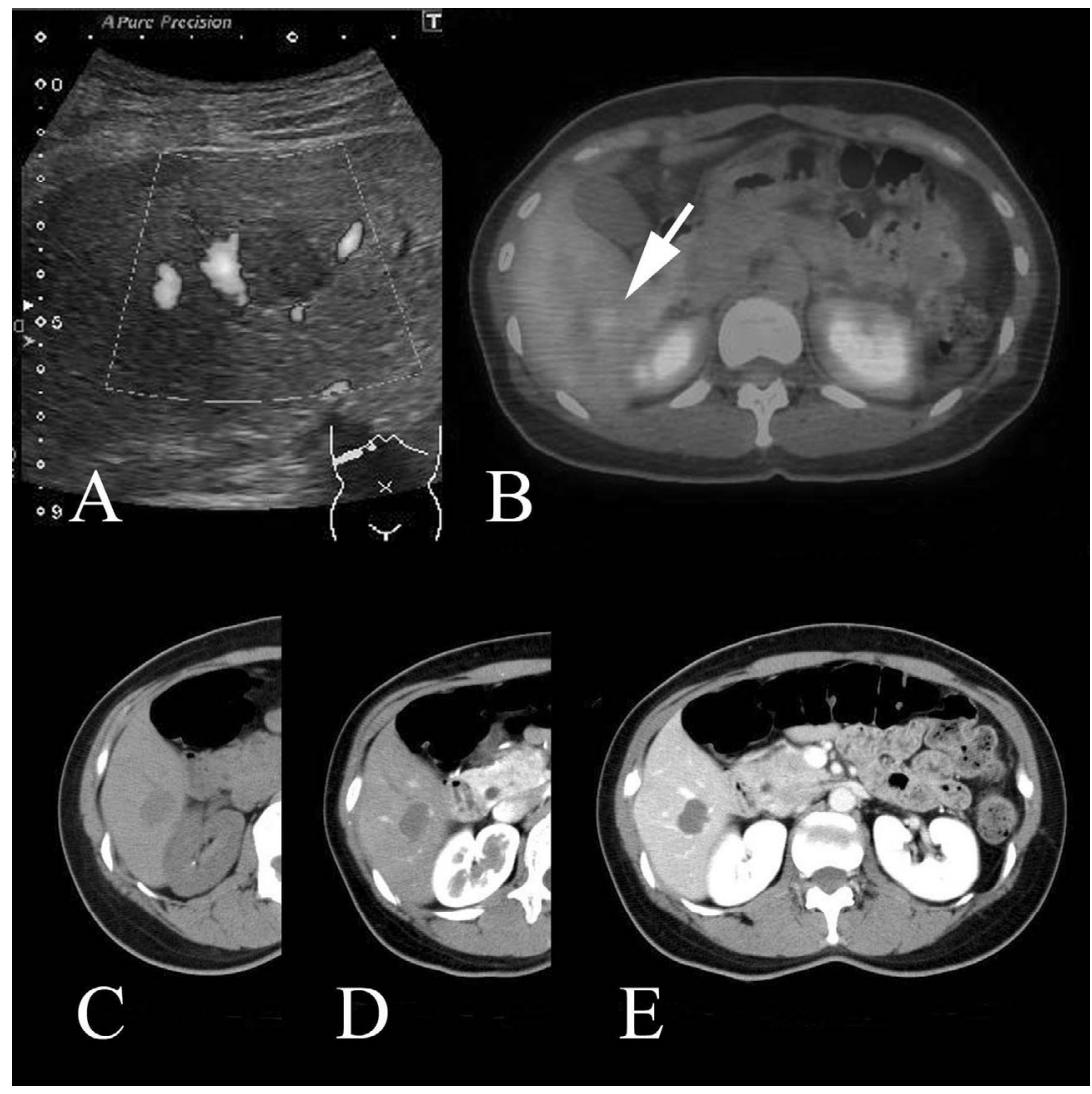

Fig. 1 Imaging series for the present case. (A) Doppler ultrasonography shows a low-echoic lesion and hyperarterial flow surrounding the lesion. (B) Positron emission tomography shows slightly high standardized uptake value in the lesion (arrow). (C-E) Dynamic computed tomography shows a low-density lesion with rim enhancement near the portal tract (arrow). mor and EGL of unknown cause. As a result, we informed the patient and her husband of the clinical options, including follow-up, biopsy or laparoscopic resection for differential diagnosis, and they decided on laparoscopic resection. Two months after presentation, laparoscopic hepatic resection of segment 6 was performed. Laparoscopically, the liver appeared normal. The cut surface of the tumor was $2.2 \times 1.7$ $\mathrm{cm}$ in size, near Glisson's sheath, and showed irregular margins and homogeneous lustrous yellow material (Fig. 3A). Microscopically, the tumor consisted of central necrotic material and peripheral granulation (Fig. 3B). The central necrotic material stained homogeneously with eosin, but contained no apparent parasitic organ or egg. Peripheral granulation contained eosinophils, monocytes, lymphocytes, macrophages, multinucleated giant cells, capillaries, and fibroblasts. No caseous necrosis, vasculitis, or Charcot-Leyden crystals were found. EGL due to unknown cause was thus diagnosed. The postoperative course was uneventful, and although peripheral eosinophils remained persistently high $(11 \%)$, the tumor has not recurred as of the time of writing, 1 year postoperatively.

\section{Discussion}

Eosinophilic granuloma is a name for the histopathologic features of a form of allergic reaction. The same histopathologic features are seen in diseases such as necrotizing vasculitis, ${ }_{1}^{1}$ sarcoidosis, ${ }^{2}$ Langerhans cell histiocytosis, Churg-Strauss syndrome, ${ }^{3}$ Kimura's disease, ${ }^{4}$ rheumatoid fever, ${ }^{5}$ hypereosinophilic syndrome, ${ }^{6}$ and allergic reactions to norfloxacin, ${ }^{7}$ glyburide, ${ }^{8}$ and parasites (fascioliasis, ascariasis, clonorchiasis, schistosomiasis, and anisakiasis). ${ }^{9-18}$ Because eosinophilic granuloma appears to represent a kind of type I allergic reaction, eosinophilic granuloma concurrently occurs systemically or in organs where type I allergic reactions arise. In a broad sense, EGL simply indicates that the liver is one of the organs where a type I allergic reaction can occur. As most EGLs are actually caused by an allergic reaction to parasites migrating through the liver, the term EGL in a narrower sense commonly indicates a specific local allergic reaction to parasites in the liver with or without digestive tract parasitosis. The parasites in question migrate to the liver from the digestive system through the portal vein, as VLM, where 
Fig. 2 Imaging series of gadoliniumethoxybenzyl-diethylenetriamine pentaacetic acid (Gd-EOB-DTPA) magnetic resonance imaging (MRI). (A) Plain MRI showed a slightly hypointense lesion (arrow). (B) Earlyphase Gd-EOB-DTPA MRI shows a hypointense lesion with rim enhancement. (C, D) Late-phase GdEOB-DTPA MRI shows a low-intensity lesion and enhancement of parenchyma in the liver.
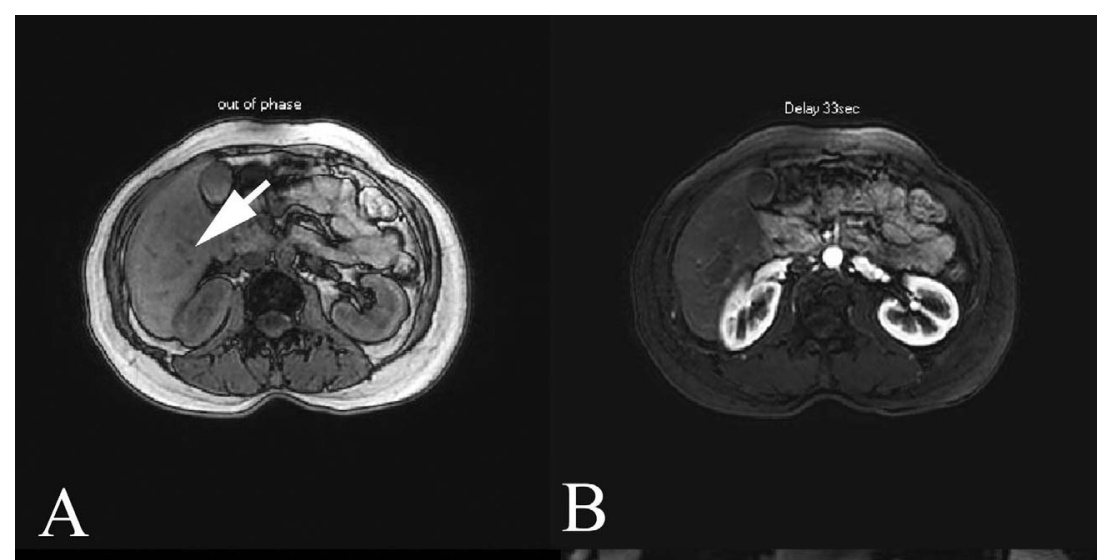

antigens from the parasites induce local allergic reactions in the liver.

Fascioliasis, ascariasis, clonorchiasis, schistosomiasis, and anisakiasis have all been reported to cause EGL by VLM. Although the patients displaying these pathologies have been reported from all generations, both sexes, and worldwide, patients tend to be children, of Asian or Middle Eastern ethnicity, and with a background of habitually eating raw meat or fish. ${ }^{17,19}$ Most cases of EGL by VLM were reportedly caused by migration of Toxocara canis. ${ }^{15}$ In Japan, cases of EGL due to
Ascaris suum are often reported in the Kyushu region, ${ }^{12,13}$ while cases in western Japan typically involve schistosomiasis. ${ }^{17}$

Clinical symptoms of EGL by VLM include fever, abdominal discomfort, general fatigue, and/or cough. However, the majority of asymptomatic patients are incidentally diagnosed with EGL by VLM when laboratory examinations reveal eosinophilia and a high ELISA titer for parasite antigens. Most adult cases of EGL by VLM show eosinophilia, while cases involving younger children and babies often show levels of eosinophils within the normal

Fig. 3 Pathologic feature of eosinophilic granuloma. (A) The tumor

macroscopically shows white-yellow coloration, and is present near Glisson's sheath (arrow). (B) The tumor histopathologically consists of inner necrotic/degenerative material and outer eosinophilic granulative inflammation. Inflammatory cells variously consist of eosinophils (arrowheads), monocytes, lymphocytes, macrophages, and

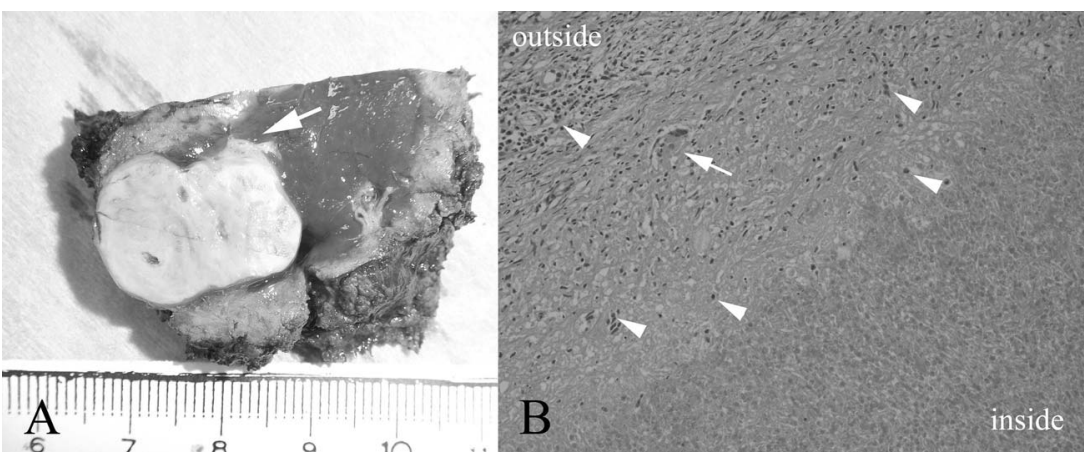

multinucleated giant cells (arrow). 
range. Sensitivities of ELISA and eosinophilia reportedly vary, although serum examination using ELISA offers the most important diagnostic clue. Some reports have documented high sensitivity and specificity of ELISA in adults and older children with EGL by VLM, ${ }^{20,21}$ while others have described low sensitivity of ELISA. ${ }^{22}$

On imaging, ${ }^{23}$ EGL by VLM appears as a macroscopic nodule, rather than microscopic diffuse inflammation. Imaging series show solitary or plural nodules with irregular shape, ranging in diameter from $5 \mathrm{~mm}$ to $2 \mathrm{~cm}$. Ultrasonographically, EGL by VLM is depicted as a low-echoic lesion, frequently accompanied by linear shadows within the nodule (bead sign). CT depicts a lesion of low density on plain imaging, and a hypodense lesion with rim enhancement in both early and late phases of dynamic enhanced CT. MRI depicts a hypointense lesion on T1-weighted imaging, and a hyperintense lesion on T2-weighted imaging. Findings on positron emission tomography (PET)-CT and Gd-EOBDTPA MRI have not previously been reported. The present case showed a lesion with slightly high standardized uptake value (SUV) on PET-CT, and low intensity with rim enhancement in the early phase of Gd-EOB-DTPA MRI and defective uptake in the late phase.

In the surgical/biopsy specimen, macroscopic examination of EGL by VLM showed a whiteyellow nodule, and microscopic features included central necrosis and peripheral infiltration of eosinophils, neutrophils, lymphocytes, epithelioid cells, and multinucleated giant cells with hyperplasia of capillaries and fibroblasts. When hyperinfiltration of eosinophils is seen, Charcot-Leyden crystals are also evident. Within the region of central necrosis, the bodies of parasites are often seen. An obstructed portal vein, ultrasonographically depicted as the "bead sign," is also frequently evident within the area of central necrosis. Some investigators have emphasized the high frequency of this "bead sign."

In general, the presence of parasites on histopathologic examination or positive ELISA results for parasites allow definitive diagnosis. When EGL by VLM is suspected, a medical interview to elicit histories of ingesting raw meat or fish, involvement in animal husbandry, or keeping pets is most important to reach a diagnosis and confirm a therapeutic plan. Referring to the medical interview, blood and serologic examinations, imaging examinations, and liver biopsy can be planned. When a patient is diagnosed with EGL by VLM and has some clinical symptoms or complaints, antiparasitic agents such as albendazole, mebendazole, thiabendazole, or diethylcarbamazine can be administered. ${ }^{24}$ When the patient is asymptomatic, followup without antiparasitic agents is usual, with periodic imaging examinations. When EGL by VLM is diagnosed, surgical resection of the granuloma is not usually performed, as most cases without clinical symptoms show spontaneous remission and disappearance of the EGL by VLM. ${ }^{23}$ Resection of EGL by VLM should be limited to cases in which confirmation of EGL is difficult.

Examinations for definitive diagnosis include ELISA and pathologic demonstration of parasites within the EGL. The sensitivity of ELISA, however, appears variable, and the rate for pathologic demonstration of parasites is low. Nakashima et al reviewed 14 cases of EGL, finding parasites in none of the cases. ${ }^{25}$ Kaplan et al also reviewed 43 cases of EGL according to histopathologic and immunohistopathologic findings, ${ }^{26}$ but failed to identify parasites in 28 cases $(65 \%)$.

In the present case, as the patient showed mild eosinophilia and no chronic hepatitis, we suspected EGL by VLM from the beginning. Physical examination, laboratory examination, and medical interviews revealed no findings specific for EGL by VLM other than eosinophilia. IgE and ELISA titers for Ascaris and Anisakis antigens showed results within normal ranges. Imaging did not demonstrate eosinophilic granulation in any other organs. In addition, the lesion in the liver did not show any improvement over the course of the 2 months before surgical treatment, and parasites were not seen in the center of the EGL on histologic examination. The possibility that the present case might not have been caused by a parasite thus cannot be excluded.

Some investigators have suggested that Glisson's sheath in the area of central necrosis represents the pathway for the flow of parasite ova from the digestive tract through the supramensenteric vein, and that the obstructed Glisson's sheath is depicted as the "bead sign" without blood flow. ${ }^{25}$ Obstruction of Glisson's sheath would induce peripheral parenchymal necrosis of the liver, and parasite ova or the parasites themselves would induce type I allergic inflammation. Presinusoidal necrosis and granulation can also be caused by copper, ${ }^{27,28}$ arsenic, $^{29}$ vinyl chloride, ${ }^{27}$ systemic mastocytosis, ${ }^{6}$ some cytotoxic drugs, ${ }^{30,31}$ and pathogenic bacteria ${ }^{32}$ such as Coxiella burne$t i i^{33}$ although inflammatory granulation does not always represent a type I allergic reaction. Some 
allergens carried by the intestinal veins (or hepatic arteries) could cause EGL in the same manner as VLM. Although most allergens ingested would be removed in feces, some residual allergens might migrate through the intestinal veins and drift from portal veins to the liver. In the present case, medical interviews, serologic examinations, and histopathologic examinations did not demonstrate VLM, although we suspected EGL caused by VLM from the beginning. The present case suggests that some solitary eosinophilic granulomas localized in the liver, as in some cases reported by Kaplan and Nakashima, ${ }^{25,26}$ might not be caused by VLM.

In conclusion, we encountered a rare case of EGL that did not demonstrate any correlation with parasitosis. The present case and some other cases, such as those reported by Kaplan and Nakashima, ${ }^{25,26}$ suggest the possibility of EGL caused by allergens other than parasites. Accumulation of more data from future cases with EGL, especially resectable cases by minimal invasive surgery and examined histopatologically, should help clarify other potential pathogeneses of EGL.

\section{Acknowledgments}

Takatsugu Yamamoto and his co-authors have no conflicts of interest, and they are not supported by any company or grant. The authors wish to thank the other surgeons of their hospital for their support.

\section{References}

1. Gambari PF, Ostuni PA, Lazzarin P, Fassina A, Todesco S. Eosinophilic granuloma and necrotizing vasculitis (ChurgStrauss syndrome?) involving a parotid gland, lymph nodes, liver and spleen. Scand J Rheumatol 1989;18(3):171-175

2. Israel HL, Margolis ML, Rose LJ. Hepatic granulomatosis and sarcoidosis. Further observations. Dig Dis Sci 1984;29(4):353356

3. Fernandes SR, Singsen BH, Hoffman GS. Sarcoidosis and systemic vasculitis. Semin Arthritis Rheum 2000;30(1):33-46

4. Kim YG, Oh JH, Lee SC, Ryu DM. Eosinophilic granuloma of soft tissue: a case report and literature review. J Oral Maxillofac Surg 1996;54(3):353-357

5. Berlin CM Jr, Boal DK, Zaino RJ, Karl SR. Hepatic granulomata. Presenting with prolonged fever. Resolution with anti-inflammatory treatment. Clin Pediatr (Phila) 1990; 29(6):339-342

6. Frieri M, Quershi M. Pediatric mastocytosis: a review of the literature. Pediatr Allergy Immunol Pulmonol 2013;26(4):175-180
7. Björnsson E, Olsson R, Remotti H. Norfloxacin-induced eosinophilic necrotizing granulomatous hepatitis. Am J Gastroenterol 2000;95(12):3662-3664

8. Saw D, Pitman E, Maung M, Savasatit P, Wasserman D, Yeung CK. Granulomatous hepatitis associated with glyburide. Dig Dis Sci 1996;41(2):322-325

9. Vercelli-Retta J, Lagios MD, Chandrasoma P. Fasciola hepatica and parasitic eosinophilic granuloma of the Liver. Am J Surg Pathol 2002;26(9):1238

10. Charatcharoenwitthaya P, Apisarnthanarak P, Pongpaibul A, Boonyaarunnate T. Eosinophilic pseudotumour of the liver. Liver Int 2012;32(2):311

11. Nishikata H, Hirata Y, Shimamura R, Dohmen K, Kudo J, Ishibashi $\mathrm{H}$ et al. A case of visceral larva migrans by Toxocara cati infection with multiple liver granuloma. J Jpn Soc Gastroenterol 1991;88(10):2697-2702

12. Hayashi, Tahara H, Yamashita K, Kuroki K, Matsushita R, Yamamoto $S$ et al. Hepatic imaging studies on patients with visceral larva migrans due to probable Ascaris suum infection. Abdom Imaging 1999;24(5):465-469

13. Hata $\mathrm{T}$, Tateishi $\mathrm{H}$, Tono $\mathrm{T}$, Okamoto $\mathrm{S}$, Okamura J, Monden $\mathrm{T}$. Hepatic eosinophilic granuloma due to visceral larva migrans of ascaris suum -A case report-. J Jpn Surg Assoc 2000;61(9): 2434-2438

14. Saito F, Okabe Y, Suga H, Watanabe T, Arinaga T, Naito Y et al. A case of hepatic eosinophilic granuloma, which needs distinction with metastatic liver cancer. J Jpn Soc Gastroenterol 2008;105(10):1509-1514

15. Fujii $\mathrm{H}$, Ito $\mathrm{T}$, Mizuno $\mathrm{H}$, Iiboshi $\mathrm{Y}$, Yamamura N, Hitora Tet al. A case of visceral larva migrans due to Toxocara canis in the liver; difficulty in making a differential diagnosis from intrahepatic metastasis of colon cancer. J Jpn Soc Surg Infect 2011;8(6):747-752

16. Sun T. Clonorchiasis: a report of four cases and discussion of unusual manifestations. Am J Trop Med Hyg 1980;29(6):12231227

17. Sanai FM, Ashraf S, Abdo AA, Satti MB, Batwa F, Al-Husseini $\mathrm{H}$ et al. Hepatic granuloma: decreasing trend in a highincidence area. Liver Int 2008;28(10):1402-1407

18. Morita M, Soyama A, Takatsuki M, Kuroki T, Abe K, Hayashi Tet al. A case of hepatic mass induced by extra-gastrointestinal anisakiasis. J Jpn Surg Assoc 2013;74(2):483-487

19. Turrientes MC, Perez de Ayala A, Norman F, Navarro M, Perez-Molina JA, Rodriquez-Ferrer $\mathrm{M}$ et al. Visceral larva migrans in immigrants from Latin America. Emerg Infect Dis 2011;17(7):1263-1265

20. Chang S, Lim JH, Choi D, Park CK, Kwon NH, Cho SY et al. Hepatic visceral larva migrans of Toxocara canis: CT and sonographic findings. AJR Am J Roentgenol 2006; 187(6):622629

21. Musso C, Castelo JS, Tsanaclis AM, Pereira FE. Prevalence of Toxocara-induced liver granulomas, detected by immunohistochemistry, in a series of autopsies at a Children's Reference 
Hospital in Vitoria, ES, Brazil. Virchows Arch 2007;450(4):411417

22. Elshazly AM, Attia G, El-Ghareeb AS, Belal US. Clinical varieties of Toxocariasis canis in Children's Hospital, Mansoura University: is it an underestimated problem? J Egypt Soc Parasitol 2011;41(2):263-274

23. Lim JH. Toxocariasis of the liver: visceral larva migrans. Abdom Imaging 2008;33(2):151-156

24. Grover JK, Vats V, Uppal G, Yadav S. Anthelmintics: a review. Trop Gastroenterol 2001;22(4):180-189

25. Nakashima O, Watanabe J, Taguchi J, Okudaira S, Nakashima $\mathrm{Y}$, Yasunaga $\mathrm{M}$ et al. Clinicopathologic study on necrotic nodules in the liver. Acta Hepatol Jpn 1994;35(7):527-535

26. Kaplan KJ, Goodman ZD, Ishak KG. Eosinophilic granuloma of the liver: a characteristic lesion with relationship to visceral larva migrans. Am J Surg Pathol 2001;25(10):1316-1321

27. Pimentel JC, Menezes AP. Liver granulomas containing copper in vineyard sprayer's lung. A new etiology of hepatic granulomatosis. Am Rev Respir Dis 1975;111(2):189-195
28. Hutchins RG, Breitschwerdt EB, Cullen JM, Bissett SA, Gookin JL. Limited yield of diagnoses of intrahepatic infectious causes of canine granulomatous hepatitis from archival liver tissue. J Vet Diagn Invest 2012;24(5):888-894

29. Pimentel JC, Menezes AP. Liver disease in vineyard sprayers. Gastroenterology 1977;72(2):275-283

30. Ishak KG, Zimmerman HJ. Drug-induced and toxic granulomatous hepatitis. Baillieres Clin Gastroenterol 1988;2(2):463-480

31. McMaster KR 3rd, Hennigar GR. Drug-induced granulomatous hepatitis. Lab Invest 1981;44(1):61-73

32. Deepe GS Jr, Taylor CL, Srivastava L, Bullock WE. Impairment of granulomatous inflammatory response to Histoplasma capsulatum by inhibitors of angiotensin-converting enzyme. Infect Immun 1985;48(2):395-401

33. Aguilar-Olivos N, del Carmen Manzano-Robleda M, Gutiérrez-Grobe Y, Chablé-Montero F, Albores-Saavedra J, LópezMéndez E. Granulomatous hepatitis caused by $Q$ fever: a differential diagnosis of fever of unknown origin. Ann Hepatol 2013;12(1):138-141 